\title{
Response to Pepperberg; Herman and Uyeyama; and Shanker, Savage-Rumbaugh, and Taylor
}

\author{
EDWARD KAKO \\ University of Pennsylvania, Philadelphia, Pennsylvania
}

\begin{abstract}
Whether the animals studied by Pepperberg, Herman, and Savage-Rumbaugh can learn prepositions remains an open and important question, though the dolphins' use of demonstratives and conjuctions suggests an impressive competence for at least some closed-class items. It is unlikely that human-like brain structure can explain the capacities of these animals. Their capacities may instead be built upon the cognitive mechanisms favored by social complexity.
\end{abstract}

In their thoughtful, stimulating commentaries, Pepperberg (1999), Herman and Uyeyama (1999), and Shanker, Savage-Rumbaugh, and Taylor (1999) have addressed a number of important issues. I will here focus on just three: closed-class items, the relations of brain structure and social complexity to linguistic capacity, and the importance of continued research on the linguistic capacities of nonhuman animals.

\section{Closed-Class Items}

I am pleased to hear that Pepperberg (1999) has proposed to teach Alex closed-class items, although I am disappointed that she has not yet done so. I disagree that Alex's success in learning in versus on (or above vs. below) would be trivial. Like Pepperberg, I strongly suspect that Alex possesses the necessary spatial concepts. The question is whether he can map those concepts onto lexical items and whether he can use those lexical items compositionally, in comprehension and production (to interpret a question like "What color hide in bowl?" or to respond to the question "Where yellow hide?" with "In bowl"). To date, Alex has succeeded in the mapping and compositional use of concepts related to object class, property, and number. It remains to be seen whether he can map and use the geometric and relational concepts relevant to prepositions.

Herman and Uyeyama (1999) present persuasive evidence that the dolphins have learned two closed-class items - the demonstrative (pronoun) THAT and the conjunction AND. I am especially impressed by their capacity to use demonstratives in the comprehension of relational commands (e.g., THAT FETCH THAT). The dolphins' mastery of LEFT and RIGHT is very striking, as these terms encode abstract, egocentric reference points. However, they are not closed-class items, but rather belong to the open-class set of nouns (at least in English). ${ }^{1}$ Whether

Correspondence concerning this article should be sent to E. Kako, Department of Psychology, University of Pennsylvania, Philadelphia, PA 19104-6196 (e-mail: kako@psych.upenn.edu) the dolphins can learn prepositions remains an open question. I agree with Herman and Uyeyama that teaching IN versus ON would require the teaching of a new verb like TAKE; otherwise, as they point out, the verb PUT would become redundant, and we would have no way of telling whether the dolphins were interpreting the string compositionally.

\section{Brains, Social Complexity, and Convergent Evolution}

Herman and Uyeyama (1999) and Shanker et al. (1999) attribute the syntactic capacities of their subjects to human-like brains. To be sure, structural similarities do exist, but so do striking differences. Although it is true, as Herman and Uyeyama say, that dolphins and humans are both highly encephalized (i.e., the brains of both species are much heavier, relative to their body weight, than are the brains of other mammals), it is also true that humans are substantially more encephalized than dolphins (Marino, 1998). Moreover, cetacean brain organization differs markedly from primate brain organization, both in morphology and in cytoarchitecture (Glezer, Jacobs, \& Morgane, 1988; Morgane \& Jacobs, 1972). Chimpanzee brains are also less encephalized than those of humans. And, although the chimpanzee brain is more human-like in organization (for obvious reasons), the chimpanzee prefrontal cortex is substantially smaller in proportion to the rest of the cortex than is the human prefrontal cortex, which is anomalously large among primates (Deacon, 1997). ${ }^{2}$ Any argument that attributes common linguistic competence to neuroanatomical similarity fares even less well when we consider the accomplishments of Alex, whose avian brain has an even more strikingly different organization.

Why, if their brains differ so much from the human brain, do these three species show competence in at least some of the core properties of human syntax? One possibility, which I explore in the General Discussion section of my paper, is that they emerge from similar ecological pressures operating to favor similar abilities - in other words, convergent cognitive evolution. This conver- 
gence may be driven in part by the demands of social complexity - including the need to keep track of individuals, their relationships, and their history of interactions (see, e.g., Barton \& Dunbar, 1997; Humphrey, 1976). Both Pepperberg (1999) and Herman and Uyeyama (1999) appear to find this suggestion attractive. Pepperberg proposes that, because parrots live in complex social systems not unlike those of primates, their "cognitive abilities, whether or not syntactically expressed, should match those of nonhuman primates" (p. 17). Herman and Uyeyama, too, emphasize the social complexity of the dolphins, noting that the learning demands imposed by social complexity require "advanced cognitive skills" (p. 22). Whether social complexity really favors the cognitive substrates necessary for linguistic competence remains to be seen. To test this hypothesis, we would need data from a wide range of language-trained species that vary in their social complexity.

\section{The Significance of This Research}

Both Pepperberg (1999) and Shanker et al. (1999) are surprisingly pessimistic about the utility of further research on the syntactic abilities of their animals. Pepperberg's stated goals are "to examine cognitive similarities and differences, and to determine what, if any, continua exist in cognitive and information processing abilities across and between species." Syntactic capacities, in her view, are "too fraught with alternative interpretations" (p. 17). Shanker et al. voice confidence that Kanzi and Panbanisha will show competence with morphosyntax (e.g., understanding that the closed-class marker $-s$ signals the plural). Yet they appear to shy away from further exploration of these capacities, because positive results cannot "lay to rest the discontinuity thesis" (p. 24). However carefully the research is done, there will no doubt be many who remain unpersuaded and rush to offer (sometimes byzantine) alternative explanations. But a lack of data will do nothing to change this situation.

I encourage Pepperberg (1999) and Shanker et al. (1999) to take the position advocated by Herman and Uyeyama (1999), who state that "the animal language work can help us to identify with more surety those processes in humans that may derive from general cognitive structures rather than from language-specific structures" (p. 22). By con- ducting crucial experiments informed by prior research on human language acquisition, we can learn more about the extent to which language is built upon other cognitive capacities and about the power of natural selection to produce similar capacities in differently organized brains.

\section{REFERENCES}

Barton, R. A., \& Dunbar, R. I. M. (1997). Evolution of the social brain. In A. Whiten \& R. W. Byrne (Eds.), Machiavellian intelligence: II. Extension and evaluations (pp. 240-263). Cambridge: Cambridge University Press.

DeACON, T. W. (1997). The symbolic species. New York: Norton.

Glezer, I. I., JacoBs, M. S., \& MorGane, P. J. (1988). Implications of the "initial brain" concept for brain evolution in Cetacea. Behavioral \& Brain Sciences, 11, 75-116.

Herman, L. M., \& Uyeyama, R. K. (1999). The dolphin's grammatical competency: Comments on Kako (1999). Animal Learning \& Behavior, 27, 18-23.

Humphrey, N. K. (1976). Social function of the intellect. In P. P. G. Bateson \& R. A. Hinde (Eds.), Growing points in ethology (pp. 303317). Cambridge: Cambridge University Press.

KAKO, E. (1999). Elements of syntax in the systems of three languagetrained animals. Animal Learning \& Behavior, 27, 1-14.

MARINO, L. (1998). A comparison of encephalization between odontocete cetaceans and anthropoid primates. Brain, Behavior \& Evolution, 51, 230-238.

Morgane, P. J., \& JaCoBs, M. S. (1972). Comparative anatomy of the cetacean nervous system. In R. J. Harrison (Ed.), Functional anatomy of marine mammals (pp. 117-244). New York: Academic Press.

PePperberg, I. M. (1999). Rethinking syntax: A commentary on E. Kako's "Elements of syntax in the systems of three languagetrained animals." Animal Learning \& Behavior, 27, 15-17.

Shanker, S. G., Savage-Rumbaugh, E. S., \& Taylor, T. J. (1999). Kanzi: A new beginning. Animal Learning \& Behavior, 27, 24-26.

\section{NOTES}

1. Because they can precede nouns, left and right might at first appear to be adjectives. However, this fact alone does not qualify a word as an adjective. Many nouns can precede other nouns in a modifying relationship (e.g., maternity dress). And left and right do not behave like adjectives in any other way. Although one can say both his skillful sewing and his left hand, only skillful can be turned into a noun or an adverb: Compare the skillfulness of his sewing and he sews skillfully with the leftness of his hand and he sews leftly. (I thank Larry Trask for this observation and for these examples.)

2. Deacon (1997) has argued that the emergence of language depended crucially on the expansion of the prefrontal cortex. Studying the linguistic capacities of animals whose prefrontal cortexes are either much smaller or absent should help to illuminate the role of this structure in human language. 